\title{
Initial Neoplastic Proliferations and Background Pathologies of Kidneys with Clear Cell Renal Carcinoma
}

\author{
Maris Sperga, Vilnis Lietuvietis, Regina Kleina \\ Riga Stradins University, Riga Eastern Clinical University Hospital
}

\begin{abstract}
Summary.
Introduction. Nephrosclerosis and development of renal tumours is desribed in literature. But there is a few dates about correlation between grades of nephrosclerosis and renal tumours.

Aim of the study. Aim of our study is to find out and to analyze initial neoplastic proliferation around renal cell carcinoma in case of nephrosclerosis of different degrees. The hypothesis: the initial neoplastic proliferation in renal cell carcinoma is related to the degree of nephrosclerosis.
\end{abstract}

Materials and methods. We investigated 206 surgical removed kidneys with clear cell renal carcinoma (RCCC) cases. To evaluate the correlation between grading of RCCC and its stages with nephrosclerosis we framed 5 macroscopic degrees of its severity. According the expression of nephrosclerosis we analyzed microscopically renal tissue to diagnose initial neoplastic proliferations.

Results. In our research we have got weak positive correlation of $R=0.2(p=0.01)$ between nephrosclerosis and grading of renal clear cell carcinoma. Practically the same correlation exists between renal tumor TNM stage and nephrosclerosis degrees. In 62 cases from all 206 examined surgically removed kidneys microscopically and grossly we have diagnosed initial neoplastic proliferations. Histological variations of them were: papillary adenoma, oncocytoma, nephrogenic adenoma and clear cell proliferations. Accordingly the localization of these neoplastic proliferations we can divide them into subcapsular, cortical and medullar both in the tumour capsule and outside it. Around the neoplastic proliferations we have evaluated the intensity of inflammation, arteriosclerosis, glomerulosclerosis, cystic transformations of renal tubules and stromal fibrosis.

Conclusions. We have proved that the most marked correlation was between the background pathologies and papillary adenoma $(n=$ 29). More common the diameter of fibrosis was several times larger than the size of adenoma. There was also strong correlation with cystic changes of renal tubules. There is a correlation $R=0.305(p=0.01)$ between the frequency of papillary adenoma findings and of nephrosclerosis stages. The second most common initial neoplastic proliferation was clear cell proliferations $(n=26)$. But it has less pronounced association with the background changes. We have not proved the correlation between the frequency of renal clear cell carcinoma and severity of nephrosclerosis.

Key words: renal clear cell carcinoma; background pathologies of kidneys; initial proliferations of tubular epithelium.

\section{INTRODUCTION}

The pathogenesis of renal epithelial tumours has provided one of the most enduring controversies of modern pathology. The renal epithelial tumours are very heterogenous group of neoplasms according to their morphological types, genetic changes, aetiological factors and prognosis. One of the problems is the association of these tumours with background renal tissue changes caused by hypertension, chronic pyelonephritis, hydronephrosis etc.

In our population there is increase of morbidity with these diseases and their complications and therefore more actual is question about the development of renal tumours. The investigations of renal tumours which have arisen in changed kidneys gives us information about monitoring and treatment opportunities.

Correlations between scar formations in organs and the development of malignancies were already mentioned by R. Virchow who wrote about chronic irritation and the development of cancer (18). In literature mainly are described renal tumours associations with terminal changes of kidneys. More common it is described in patients with papillary adenoma $(1,3)$. At the terminal renal failure the risk for the renal tumour development is maximal but histological variations and frequency of appearance are various in different districts of world. Patients with haemodialysis have also higher chance for the appearance of tumours in prostate, urinary and haematopoietic system, liver, oral cavity but there are lack of connections with risk of development of breast, gastric, rectal and lung cancer (6). Renal tumours have the characteristic feature of the development of pseudocapsule. In this zone sometimes are described tiny neoplastic and displastic changes of renal tubular epithelium (7). In literature there are few dates about correlations between the degree of nephrosclerosis and the development of renal tumours.

Kidneys rather common are involved in a lot of congenital tumours' syndromes. Mutations occur in the germinative cells and therefore there is possible to diagnose syndrome and to detect asymptomatic gene carrier (16). There are described some syndromes (von Hippel- Lindau, Birt-Hogg- Dube, Tuberous sclerosis) with typical renal tumours and their interdependences 
(5).The term "initial neoplastic proliferations" is used accordingly to microscopic findings of very small lesions starting of $5 \mathrm{~mm}$ in diameter.

\section{AIM OF THE STUDY}

Aim of our study is to find out and to analyze initial neoplastic proliferations around clear cell renal carcinoma in case of nephrosclerosis of different degrees. The hypothesis: the initial neoplastic proliferation in renal cell carcinoma is related to the degree of nephrosclerosis.

\section{MATERIALS AND METHODS}

We have analyzed grossly and microscopically changes of 304 surgically removed kidneys in the years of $2004-$ 2007 with renal cell carcinoma. 151 (49.7\%) were male and 153(50.3\%) - female. Ratio male:female was 0,85:1. The age of patients varied from 22 till 81 year, average age was $61.5 \pm 11,8$. Division of patients according their age is showed in the l.figure. Accordingly the frequency or renal cell tumours we have found such neoplasms: clear cell carcinoma (RCCC), oncocytoma, papillary renal cell carcinoma, chromophobe renal cell carcinoma. Distribution of renal tumours is showed in table No.1. From all renal tumours RCCC was found in 67,8\% $(n=206)$ of cases. The average age of these patients was $61.96 \pm 0,741$. Ratio male to female was 1:0,86. Grading of RCCC was done accordingly Thones at al., 1986. It is shown in table No.2.

RCCC were subdivided into groups according to TNM classification (5). It is shown in table No.3.

For the grossly evaluation of nephrosclerosis we have created some criteria for the degrees of nephroscerosis. We noted normal anatomical kidney size and terminal pyelonephritic scrinkage as values of ends of ranges. Other degree scores in literature are not described.

0 degree of nephroscerosis: kidney is normal in size (11$12 \mathrm{~cm}$ long, 5-7 cm wide and 2,5-3 cm thick), weight: $115-170 \mathrm{~g}(11)$.

1. degree: Kidney is not smaller in size but there are some small areas of nephrosclerosis 1 till 5\% from total surface, weight - 115-170 g

2. degree:Weight of kidney is around $80 \%$ from normal weight. Renal surface is with scars or diffuse granularity for 10-20\% from total surface of kidney.

3. degree: Weight of kidney is 70-80\%, but fibrosis occupies $20-30 \%$ of renal surface

4. degree: Weight of kidney is $50-60 \%$ of normal weight of organ and fibrosis takes $30-40 \%$ of renal surface or there is diffuse granularity.

5. degree: Weight is till $50 \%$ of normal renal weight with wide scars of kidneys what is described as terminal pyelonephritic scrinkage (17).

For the microscopic examination tissues from nephrectomies were fixed in 10\% neutral buffered formalin, after dehidratation and embedding in paraffin 4-5 microns thick specimens were stained

with hematoxylin eosin. In case of initial neoplastic proliferations we evaluated intensity of inflammation, microcystic lesions, three stages of glomerulosclerosis and arteriosclerosis.
Evaluation of inflammatory processes around tumours was expressed into 3 degrees accordingly the amount of inflammatory cells in 1 field of vision $200 x$ (in $1,26 \mathrm{~mm}^{2}$ ): weak (degree 1)- till 50 cells, mild (degree 2) - 50-200 cells and severe (degree 3) - more than 200 cells.

Microcystic lesions were evaluated accordingly such stages:

Stage 1: one cystic structure in two 100x magnification fields of vision.

Stage 2: one cystic structure in one of 100x magnification field.

Stage 3: three or more cystic structures in one 100x magnification field.

The expression of glomerulosclerosis we divided in such stages:

Stage 1: $0-10 \%$ of glomeruli are affected by fibrosis near the neoplastic proliferation;

Stage 2: $10-40 \%$ affected glomeruli; Stage 3: $40 \%$ and more affected glomeruli. But arteriosclerosis was noted as presence or lack of it.

We estimated ratio between diameter of tumour and surrounding fibrosis. Measurements were provided in millimeters. Results were divided into scales of nominals, rangs and intervals. For the comparison of two independent numbers we have used t-test. We detected also Spearman' s and Kendel tests $(p=0,01)$. All calculations were done by SPSS 13 program in Windows XP.

\section{RESULTS}

Correlations between tumour grading and severity of nephrosclerosis are shown in table No.4.

Statistical reliable correlation was found between the grading of clear cell carcinoma and the degree of nephrosclerosis. Spearman correlation $\mathrm{R}=0.2(\mathrm{p}=0.01)$. During investigations of the pseudocapsule of tumours and nearby areas we often found small neoplastic proliferations of clear cells - accumulations of eosinophylic cells and dysplastic changes of tubular epithelium. Such changes were proved in $38.8 \%(\mathrm{n}=87)$ of clear cell renal carcinomas cases.

Microscopic investigations of the pseudocapsule of RCCC and tissues nearby it have shown papillary adenoma in 29 cases of totaly examined 206 kidneys (Figure No.2). Accordingly the location of papillary adenoma in 10 cases they were detected in the pseudocapsule of tumour (figure No.2) but in 6 cases a little bit further in cortical part. Papillary adenomas elsewhere in the parenchyma outside the tumor area were found in 13 cases: 11 in subcapsular and 2 in cortical part. Of 29 papillary adenoma cases, multiple growth character was found in 12 cases with more than 1 papillary adenoma. In 8 of these cases multiple growth character was detected at the capsule of tumour.

Papillarity histologically is characterized by tubularypapillar and tubular formations in diameter from 0.01 $\mathrm{mm}$ to $3 \mathrm{~mm}$. The arithmetical average of diameter of these changes was $1.3 \pm 1.2 \mathrm{~mm}$. The ratio of diameter of the adenoma and surrounding fibrosis was between $0,03-0,5$ in $81 \%$ cases but ratio of $0.6-1.0$ was found in $19 \%$ of tumours. 
Cystic transformation in the adenomas was detected in $85 \%$ of cases. In 10 cases it was of 3 rd stage and in 7 cases of 2 nd stage. Glomerulosclerosis at adenomas was fixed in $57.1 \%$. In 7 cases as 3rd stage and in 6 cases as 2nd stage.

Vascular fibrosis at the adenoma was observed in $77.2 \%$ of cases. Intensity of inflammation was as follows: 1. degree was found in $20 \%$ of cases, 2.-in $76 \%$ and 3. degree in $14 \%$ of cases. Papillary adenomas was in $36.3 \%$ cases with G1, $40.9 \%$ of G2 and $22.8 \%$ in G3 of RCCC tumors.

The adenomas were found in $45.4 \%$ of clear cell carcinoma of stage $\mathrm{Tla}, 27.2 \%$-stage $\mathrm{Tlb}, 4.5 \%-\mathrm{T} 2-$ stage and $22.9 \%$ - T3 stage.

There is a correlation between the macroscopic degrees of severity of nephrosclerosis and the frequency of papillary adenoma findings (Kendall correlation $\mathrm{R}=$ $0.305, \mathrm{p}=0.01$ ).

Proliferations of clear cells in kidneys with the clear cell renal carcinomas were detected in 26 cases. (12.6\%); size of them was from $0.1 \mathrm{~mm}$ to $4.0 \mathrm{~mm}$. The average number of diameter was $1.2 \mathrm{~mm} \pm 1.23 \mathrm{~mm}$. Multiple proliferations were diagnosed in 12 cases. In six cases was combination with other tumour - papillary adenoma. At the vicinity of RCCC there were found clear cell proliferations in 11 cases. 3 of them were situated in subcapsular area and 8 - in cortical part. Mainly we have found compact design of tumors with tubular structures. Proliferations of clear cells in $60 \%$ of cases were detected in the adjacent renal tubular epithelial dysplastic changes (Figure No.3). Ratio of the diameter of proliferations and fibrosis was from 0.01-0,5 in $65,3 \%$ but from $0.6-1.0$. in $34.7 \%$ of the cases. Cystic changes were detected in $15.3 \%$ of cases. In all cases these lesions were of 1 st degree. Glomerulosclerosis was detected in $53.8 \%$ of analyzed tumours. In 7 cases it was of 2 nd degree but in 3 cases it was glomerulosclerosis of 3rd degree. Vascular fibrosis we have found in $57.6 \%$ of cases. Weak inflammatory reaction of first degree was seen in $26.9 \%$ of cases, but mild ( $2^{\text {nd }}$ degree) in $23.1 \%$. Macroscopically the expression of nephrosclerotic was of 2. and 3. degree. There was no correlation between the degrees of nephrosclerosis and frequency of clear cells proliferations. Foci of clear cell proliferations were in $38.4 \%$ of G1, $38.4 \%$ of G2, $23.2 \%$ of G3 RCCC. Renal cancers with clear cell proliferations were at such stages $46.3 \%-\mathrm{Tla}, 30.7 \%-\mathrm{Tl}$, $11.5 \%-\mathrm{T} 2$ un $11.5 \%$ at T3. The investigation of changes nearby the clear cell renal carcinoma and other parenchymal zones identified 3 cases with oncocytic adenoma. In one case, oncocytic adenoma was found in the tumour capsule of cortical part (Figure No. 4) but others - in cortical areas of the kidney. Microscopically they consist of small cysts covered by middle sized eosinophylic cells.

Histologically oncocytic proliferates ranged from $0.5-$ $1.0 \mathrm{~mm}$ in diameter. In two cases the background of fibrosis was not observed at all. But in one case in the background was a massive fibrosis (Figure No.4). Cystic lesions of renal tubules were observed in one case. Glomerulosclerosis was not observed. In two cases, inflammatory changes were weak - of first degree and in one case - of $3^{\text {rd }}$ degree. Arteriosclerosis was not found. There is lack of correlations between the expression of nephrosclerosis and frequency of oncocytic adenomas. In one case oncocytic adenoma was found in kidney with G 1 clear cell carcinoma and in two patients with G2 tumour. Stages of neoplasms were at T la and one in T $1 \mathrm{~b}$. Microscopical research of kidneys with RCCC proved 3 angiomyolipomas too. All these satellite tumors were found in subcapsular zone away from RCCC, their diameter was $0.3-0.8 \mathrm{~cm}$. Angiomyolipoma is characterized by the proliferation of smooth muscle cells who was strongly shielded from the surrounding stroma without capsule around them (Figure No 5). In the wall of this tumour were multiple muscular type arteries with radially arranged perivascular epitheloid cells. In two cases were few fat tissues but in one fat tissues occupied $40 \%$ of stroma. Cystical changes of renal tubules nearby angiomyolipoma were observed in non of cases. The ratio of diameter of neoplasm and surrounding fibrosis was 1.0. Glomerulosclerosis and arteriosclerosis was not found in these cases. Inflammatory reaction was of $1^{\text {st }}$ degree in all cases. Macroscopical stage of nephrosclerosis was of $3^{\text {rd }}$ degree. In one case angiomyolipoma was in patient with G 1 RCCC and in two cases with G2 cancer. In 2 kidneys angiomyolipoma was parallel with carcinoma of T1b stage and in 1 kidney with T2.During careful examination of the renal CCC background we have found also nephrogenic adenoma in 63 year old female with $6 \mathrm{~cm}$ large RCCC. It was situated nearby primary renal CCC in medullary part of kidney (figure No.6). Histologically tumour was built up from tubular elements and structures were covered by urothelium 1,0 mm diameter. Epithelium formed tubules like shapes (figure No.7). Nephrogenic adenoma was found in scarified tissues at the renal clear cell carcinoma of G2 stage. Besides there were arteriosclerosis, but inflammatory reaction was of third degree.

\section{DISCUSSION}

The most common form of renal cancers in adults was renal clear cell carcinoma. In our study it was $67.8 \%$ of all kidney tumors. Renal cell carcinomas have a high ability to induce inflammatory changes in the same tumor and adjacent tissue, with marked angiomatosis (8, 13). Therefore around renal cell carcinoma changes are mostly expressed. Some researchers indicate increased neoplastic processes in the areas of nephrosclerosis (12). Finding of neoplastic proliferations in these places, raise several problems in the diagnosis of such changes in routine hematoxylin eosin specomens. Several authors as a precancerous condition note intratubular and intracystic epithelial neoplasia. This problem is still not solved (7). When Yorukoglu K et al. (1999) analyzed the renal tubular epithelium in $5 \%$ of the cases they have found "carcinoma in situ" changes (19). In this investigation they proved that these lesions of tubular epithelium are phenotypicaly correspondent to dysplasia. The authors consider that ischemic situation in the tissues cause metabolic disturbances in tubular 
epithelium. Changes were characterized by clarifying of epithelium and imitation of clear cell proliferation $(13,4$.$) In case of tubular disturbances may occur$ also mitosis (2). In these structures are also marked immunohistochemical changes (15). On the other hand, each tumour begins as a single cell proliferation areas with features of dysplasia. Such changes were often found in microscopic tumors in the immediate context of with previous tubular epithelial structures. When we analyzed the type of neoplasia and their correlation with changes in the background, in the areas of nephrosclerosis the most common satellite tumour was papillary adenoma. It correlates with dates of other authors but they discuss these problems in polycystic disease of kidneys and in cases of hemodialysis (3). We have proved that renal CCC mainly has developed in the areas of nephrosclerosis. But in case of oncocytic adenomas such correlation was not found. Nephrogenic adenoma is rare pathology and pathologists consider this tumour as metaplastic process of urothelium without real neoplastic transformation (10). But in renal transplants is proved that nephrogenic adenoma is of tubular epithelium origin (9).

\section{CONCLUSIONS}

1. Background pathologies around tumour are typical for clear cell renal carcinoma in different stages and with various grading of it opposite to other neoplasms of kidney.

2. In association with severe nephrosclerosis with terminal shrinkage of kidney we have detected only Gl clear cell renal carcinoma and neoplastic proliferations in the zones of nephrosclerosis were also of Gl grade.

3. Our research has proved positive correlation between the type of tumour and cystic changes in tubules and arteriosclerosis but we found weak correlation with glomerulosclerosis and inflammation.

4. The most frequent type of tumor which was in association with nephrosclerosis and clear cell renal carcinoma was papillary adenoma.

\section{Conflict of interest: None}

\section{REFERENCES}

1. Budin RE, McDonell PJ. Renal cell neoplasms. Their relationsship to arteriolosclerosis // Arch Pathol Lab Med, 1984; 108:408-414

2. Bonventre JV. Dedifferentation and proliferation of surviving epithelial cells in acute renal failure // J Am Soc Nephro, 2003; 14: 55 - 61

3. Hugson MD, Hennigar GR, McManus JFA. Atypical cysts, aquired renal cystic disease, and renal cell tumours in end stage dialyssis kidney // Lb Invest, $1980 ; 475-480$

4. Hughson MD, McManus JFA, Fitts CT, Williams AV. Studies of end-stage kidneys. 3. Glycogen deposition in interstitial cells of the renal medulla // Am J Clin Pathol, 1979; 72:400 - 404

5. John N. Eble, Guido Sauter, Jonathan I. Epstein $\delta$ Isabell A. Sesterhenn World Health Organization
Classification of Tumors. Pathology \& Genetics. Tumors of the Urinary System and Male Genital Organs. // In: Merino MJ, Eccles DM, Linehan WM. Familial renal cell carcinoma. IARC Press Lyon; 2004; $15-22$

6. Teschner M, Garte C, Ruckle-Lanz H, Maeder U, Stopper H, Klassen A, Heidland A. Inzidenz und Spektrum maligner Erkrankungen bei Dialysepatienten in Nordbayern // Dtsch Med Wochenschr 2002; 127:2497 - 2502

7. Mourad WA, Nestok BR, Saleh GY, Solez K, Power RF, Jewell LD. Dysplastic tubular epithelium in "normal" kidney associated with renal cell carcinoma // Am.J.Surg Pathol. 1994; 18:1117 - 24

8. Maxwell PH, Wiesener MS, Chang GW, Clifford SC, Vaux EC, Cockman ME, Wykoff CC, Pugh CW, Maher ER, Ratcliffe PJ. The tumoru supressor protein VHL targets hypoxia- inducible factors for oxygendepend proteolysis // Nature, 1999; 399:271 275

9. Maza PR, Schaufler R, Altenhuber-Muller R et all. Derivation of nephrogenic adenomas from renal tubular cells in kidney transplantant recipients // N Engl J Med, 2002; 29:653 - 659

10. McIntire TL, Soloway MS, Murphy WM. Nepfrogenic adenoma // Urology, 1987; 29:237 - 241

11. Ming Zhou. Genitourinary Pathology // In: Stephen M. Non-neoplastic Diseases of the Kidney. Churchill Livingstone; 2007; $225-228$

12. Raikhlin NT, Petrov SV // Manual on immunohistochemical diagnostics of human tumours // In: Romanenko AM, Llommbart-Bosch A. Immunochichemical diagnosis tumours of kidney. Kazan: Titul; 2004; $93-100$

13. Remmele W // Pathologie 3. Urogentialorgane. Mamma. Endokrine Organe Kinderpathologie. Bewegungsapparat (auser Muskulatur) Haut // In: Schubert GE. Niere und ableitende Harnwege. Stuttgart: Springer-Verlag; 1984; $92-100$

14. Sperga M, Kleina R. Analyses of Cell Proliferation Kinetics, Angiogenesis and Expression of Transmembrane Glycoprotein in Papillary Renall Adenomas and Carcinomas // Cell Biology International, 2005; 29:1112-1113

15. Stoerkel St // Karzinome und Onkozytome der Niere. Stuttgart: Gustav Fisher Verlag; 1993; 19 20

16. Stolle C, Glenn G, Zbar B, Humprey JS, Choyke P, Walther M, Pack S, Hurley K, Andrey C, Klausner $\mathrm{R}$, Linehan WM. Improved detection of germline mutations in the von Hippel- Lindau disease tumor suppresor gene // Hum Mutat, 1998; 12:417 - 423

17. Ursus- Nikolaus Riede, Hans- Erkart Schaefer. // Allgemeine und spezielle Pathologie. In: Riede UN, Wehner H. Nieren. Stuttgart: Thieme Verlag; 1993; $820-825$

18. Walter JW, Israel MS.// General Pathology. London: Churchil Livingstone; 1982; $252-256$

19. Yorukoglu K, Actas S, Mungan M, Kirkali Z. Tubular displasia and carcinoma in situ: precursor of renal cell carcinoma // Urol, 1999; 5:684-689 


\section{Address:}

Maris Sperga

Riga Eastern Clinical University Hospital

Department of Pathology

Hipokrata Street 2

Riga, Latvia, LV-1038

E-mail: spergamaris@hotmail.com

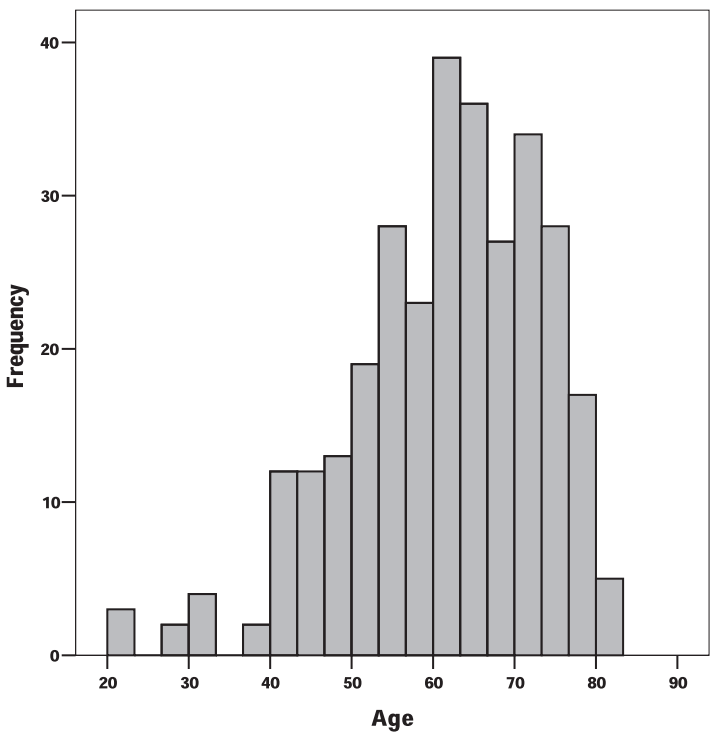

Fig. 1. The histogram of distribution of patients with renal tumours according the age
Tab. 1. Distribution of renal tumours accordingly the frequency

\begin{tabular}{|c|c|c|}
\hline Diagnoses & Number & $\%$ \\
\hline Clear cell carcinoma & 206 & 67,8 \\
\hline Oncocytoma & 30 & 9,9 \\
\hline Papillary renal cell carcinoma & 22 & 7,2 \\
\hline $\begin{array}{c}\text { Chromophobe renal cell } \\
\text { carcinoma }\end{array}$ & 23 & 7,6 \\
\hline Other tumours & 23 & 7,5 \\
\hline Total & 304 & 100,0 \\
\hline
\end{tabular}

Table 2. Grading of RCCC cases according Thoenes

\begin{tabular}{|c|c|c|}
\hline $\begin{array}{c}\text { Grade of tumours } \\
\text { (Thoenes) }\end{array}$ & Frequency & $\begin{array}{c}\text { Percent } \\
\%\end{array}$ \\
\hline 1 & 71 & 34,5 \\
\hline 2 & 89 & 43,2 \\
\hline 3 & 46 & 22,3 \\
\hline Total & 206 & 100 \\
\hline
\end{tabular}

Tab. 3. TNM stage frequencies of RCCC

\begin{tabular}{|c|c|c|}
\hline TNM stage of RCCC & Frequency & $\begin{array}{c}\text { Percent } \\
\%\end{array}$ \\
\hline Tla & 81 & 39,3 \\
\hline T1b & 62 & 30,9 \\
\hline T2 & 42 & 20,3 \\
\hline T3a & 12 & 5,8 \\
\hline T3b & 7 & 3,4 \\
\hline T4 & 2 & 0,9 \\
\hline Total & 206 & 100 \\
\hline
\end{tabular}

Table 4. Correlations of tumour grading and severity of nephrosclerosis

\begin{tabular}{|c|c|c|c|}
\hline Degree of nephrosclerosis & \multicolumn{3}{|c|}{ Grading (Thoenes) } \\
\cline { 2 - 4 } & G1 & G2 & G3 \\
\hline 0 & & 1 & \\
\hline 1 & 31 & 47 & 29 \\
\hline 2 & 19 & 26 & 25 \\
\hline 3 & 16 & 14 & 2 \\
\hline 4 & 4 & 1 & \\
\hline 5 & 1 & & \\
\hline
\end{tabular}




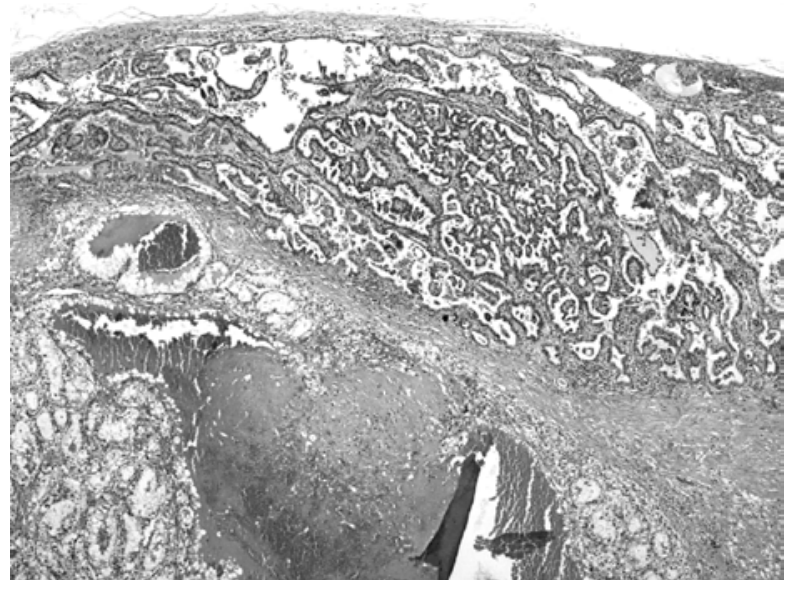

Fig. 2. Papillary adenoma (above) in the pseudocapsule of renal clear cell carcinoma (beneath). Hemotoxilin-eosin. x 40

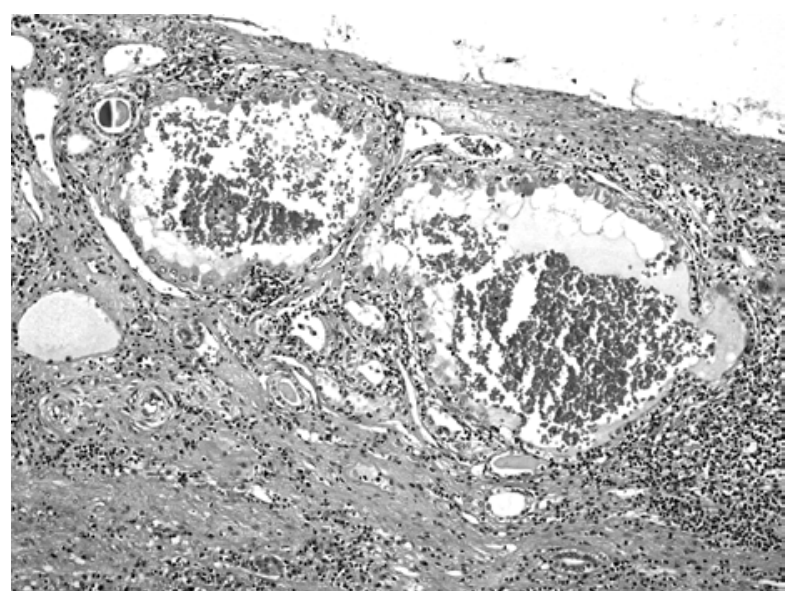

Fig. 4. Oncocytic adenoma in the area of severe nephrosclerosis nearby the clear cell carcinoma. H/E X100

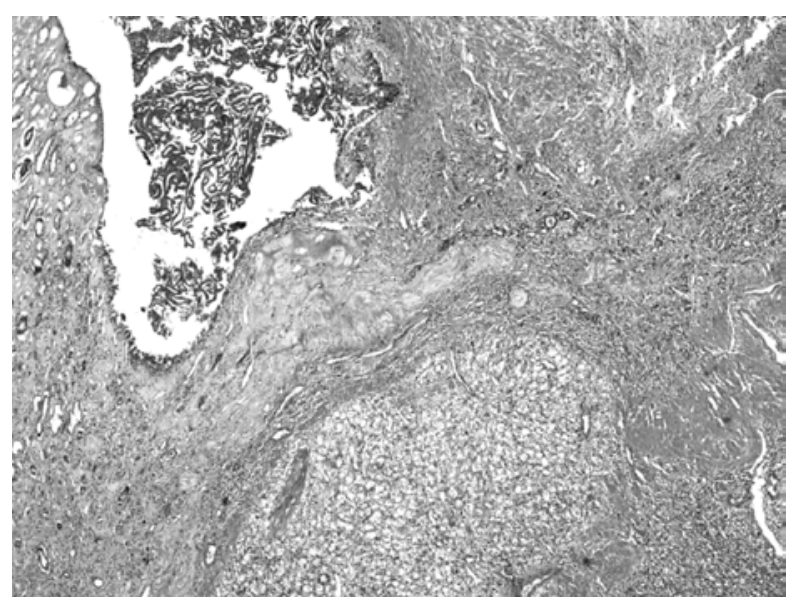

Fig. 6. Nephrogenic adenoma (above) situated at the renal CC carcinoma (beneath). Hemotoxilineosin $x 40$

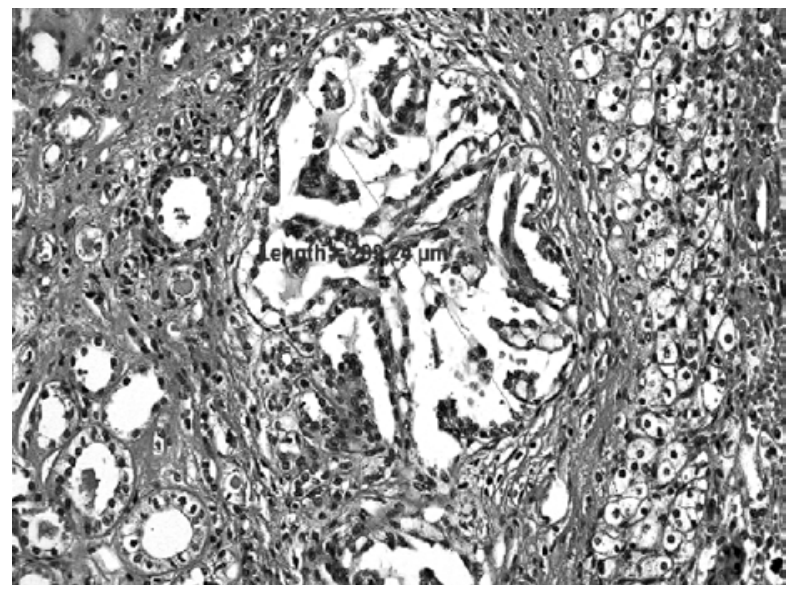

Fig. 3. Clear cell proliferations foci in pseidocapsula of RCCC. There is visible displastic changes of tubular epithelium with early clear cell differentiation. Hematoxilin-eosin. x100

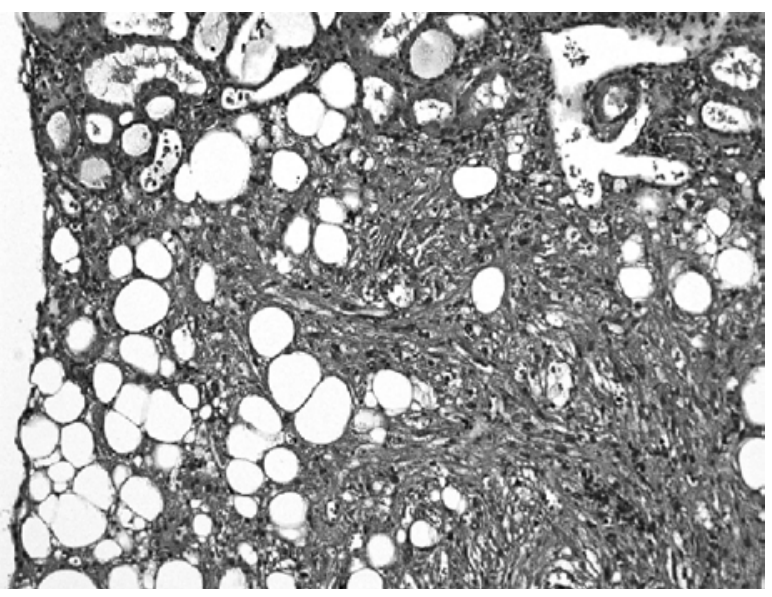

Fig. 5. Angiomyolipoma with smooth muscle cells and fat tissue. Hemotoxilin-eosin. x100

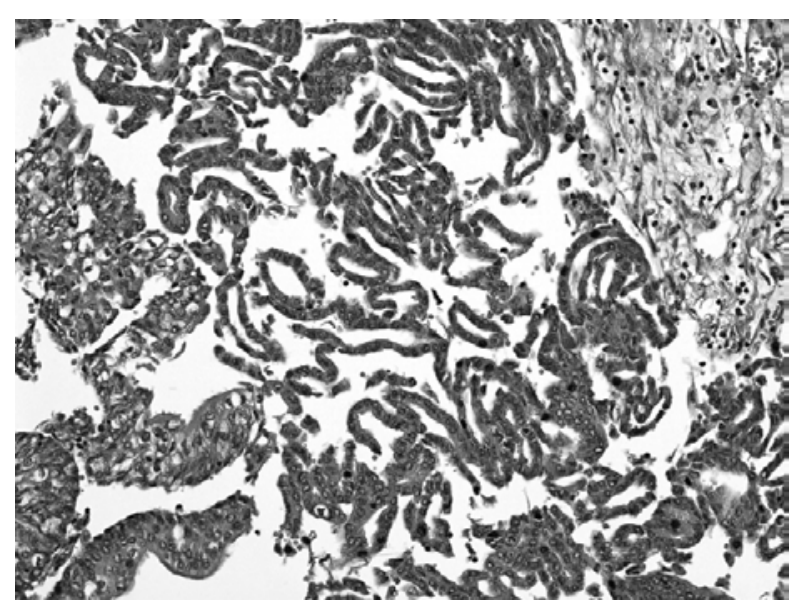

Fig. 7. Nephrogenic adenoma consists of solid tubular structures with eosinofilic epithelium. There are seen connection with urothelium. Lesion from fig. No. 6. X 200 